\section{NECESIDAD DE CONSENSO EN EL DIAGNÓSTICO DE LA TOXOCARIASIS HUMANA: IMPLICACIONES EN LA SALUD PÚBLICA LATINOAMERICANA}

\section{[NEED FOR A CONSENSUS IN THE DIAGNOSIS OF HUMAN TOXOCARIASIS: IMPLICATIONS FOR THE LATIN AMERICAN PUBLIC HEALTH]}

\author{
Alfonso J. Rodríguez-Morales 1,2,a, \\ Luis Felipe Echeverri-Cataño ${ }^{3, b}$, Olinda Delgado 2,c
}

Sr. Editor. Hemos leído con gran interés el artículo de revisión que recientemente han publicado Roldán y cols (1) sobre diagnóstico de la toxocariasis humana. Celebramos el hecho que se haya publicado, considerando la gran necesidad que existe de caracterizar epidemiológicamente una zoonosis parasitaria que ha sido poco tomada en cuenta a nivel mundial y en América Latina. De acuerdo con los limitados estudios hechos en las últimas décadas se puede estimar una seroprevalencia regional que oscilaría entre 1,8 a $66,6 \%{ }^{(2)}$.

En toxocariasis existe una clara necesidad de establecer una mayor profundización, no solo de investigaciones que estén particularmente orientadas a mejorar el diagnóstico etiológico, inmunológico y molecular, sino también de generar espacios para la discusión entre expertos en el tema y generar consensos diagnósticos aún inexistentes en esta enfermedad. Establecer un diagnóstico certero en toxocariasis se constituye entonces, como un hecho excepcional y, en la mayoría de las oportunidades, se realiza basándose en un buen juicio clínico y epidemiológico, aunado a alguna de las pruebas diagnósticas referidas por Roldán y cols ${ }^{(1)}$ y por otros autores ${ }^{(2)}$.

Sin embargo, quisiéramos comentar sobre la prueba ELISA-IgG Avidez, internacionalmente referida en la literatura como utilidad diagnóstica para toxocariasis en el año $2008^{(3)}$, ya empleada en protocolos de investigación en la Sección de Inmunoparasitología del

\footnotetext{
Cátedra de Salud Pública, Departamento de Medicina Preventiva y Social, Escuela de Medicina Luis Razetti, Facultad de Medicina, Universidad Central de Venezuela, Caracas, Venezuela.

2 Sección de Inmunoparasitología, Piso 1, Instituto de Medicina Tropical, Universidad Central de Venezuela, Caracas, Venezuela.

3 Programa de Medicina, Facultad de Ciencias de la Salud, Universidad Tecnológica de Pereira, Pereira, Risaralda, Colombia.

a Médico Tropicalista; b Estudiante de Medicina, ' Doctora en Parasitología
}

Recibido: 10-01-11 Aprobado: 12-01-11
Instituto de Medicina Tropical de la Universidad Central de Venezuela ${ }^{(4)}$ desde el año 2005. Esta prueba ha empezado a ser usada no solo en investigación, sino también en el diagnóstico rutinario en servicios de salud, como es el caso de su empleo en la sección mencionada desde el año $2008{ }^{(5)}$.

Celebramos la publicación de este tipo de artículos $\mathrm{y}$, al mismo tiempo, queremos hacer hincapié en la relevancia de establecer la especificidad de la técnica nombrada, tal y como se menciona en los trabajos referidos y la revisión hecha por Roldán y cols ${ }^{(1)}$. Es por esto, que en eventos como el Congreso Latinoamericano de Parasitología, organizado por la Federación Latinoamericana de Parasitología (FLAP), deberían hacerse reuniones para tales fines: llegar a un consenso sobre los criterios diagnósticos en la toxocariasis humana y hacer recomendaciones sobre la utilidad de las pruebas diagnósticas disponibles, contando con expertos de diferentes países trabajando en el tema. Esta podría ser, además, una reflexión para el venidero Congreso FLAP 2011 que se realizará en Bogotá, Colombia.

Todo ello tiene importantes implicaciones en la salud pública, no solo latinoamericana sino también mundial, pues como se mencionó previamente, existe una gran variabilidad en las cifras reportadas de seroprevalencia. Más aun, la toxocariasis humana es una enfermedad que poco se registra o se notifica rutinariamente ante los estamentos pertinentes en diversos países, lo que dificulta establecer su prevalencia, incidencia, carga de enfermedad, morbilidad en general, e incluso mortalidad, razón que hace surgir la necesidad de establecer los anteriores descriptores investigativos de la enfermedad.

Dada la gran existencia de factores de riesgo en las zonas rurales y suburbanas de casi todos los países latinoamericanos, la presencia de perros y gatos, sumado a la falta de control veterinario y precarias condiciones de higiene, es apenas lógico argumentar y esperar que las cifras en muchos casos correspondan a una realidad poblacional diferente a la que se reporta hasta el momento.

Considerar la toxocariasis como una enfermedad infrecuente puede llevar al facultativo desprevenido a ignorar la sintomatología, obviando lo importante que pueden llegar a ser tanto las manifestaciones clínicas (debe recordarse que en muchos ocasiones puede también haber casos asintomáticos) y sus consecuencias en la salud a corto, mediano y largo plazo, a veces incluso graves o fatales. Es el caso del síndrome de larva migrans visceral, especialmente en niños; o 
la discapacidad visual consecuente en la toxocariasis ocular, la cual debe siempre considerarse como diagnóstico diferencial con tumores de la retina como el retinoblastoma ${ }^{(2)}$.

Como hemos sugerido previamente ${ }^{(2)}$, sería de gran importancia que las autoridades de salud nacionales consideraran la relevancia epidemiológica de su registro en términos de morbilidad y mortalidad, ausentes en los reportes epidemiológicos correspondientes, con el fin de mejorar la comprensión de la epidemiología de la enfermedad en América Latina y avanzar así en el diseño de políticas en salud pública. Conocer mejor la enfermedad, incluyendo el mejorar su diagnóstico, permite una mejor prevención y control de esta importante enfermedad infecciosa en nuestra región.

\section{Conflictos de Interés}

Los autores declaran no tener conflictos de interés en la publicación de este artículo.

\section{REFERENCIAS BIBLIOGRÁFICAS}

1. Roldan W, Espinoza YA, Huapaya PE, Jimenez S. Diagnóstico de toxocarosis humana. Rev Peru Med Exp Salud Publica. 2010; 27(4):613-620.

2. Delgado 0 , Rodriguez-Morales AJ. Aspectos clínicoepidemiológicos de la toxocariasis: una enfermedad desatendida en Venezuela y América Latina. Bol Mal Salud Amb. 2009;49(1):1-33.

3. Dziemian E, Zarnowska H, Kolodziej-Sobocinska M, Machnicka B. Determination of the relative avidity of the specific IgG antibodies in human Toxocariasis. Parasite Immunol. 2008;30(3):187-190.

4. Coraspe V, Baptista R, Guerra I, Rivas M, Silva S, Fernandez $J$, et al. Detección de casos activos de Toxocariosis visceral mediante la prueba de Elisa-AvidezIgG. Parasitol Latinoam 2005; 60: T248-T249. (Resumen de Congreso).

5. Delgado O, Ortegoza J, Coraspe V, Rodriguez-Morales AJ. Toxocariasis phase-specific diagnosis in children from Venezuela rural areas using specific IgG antibodies relative avidity. Int J Antimicrob Agents. 2009; 34(Supplement 2):S64.

Correspondencia: Alfonso J. Rodríguez-Morales.

Dirección: Sección de Inmunoparasitología, Piso 1, Instituto de Medicina Tropical, UCV, Ciudad Universitaria. Caracas 1050, Venezuela. E.

Correo electrónico: alfonsorm@ula.ve

\section{¿TRANSMISIÓN VERTICAL O CIRCUNSTANCIAL? \\ [VERTICAL OR CIRCUMSTANTIAL TRANSMISSION?]}

José Luis Sandoval Gutiérrez ${ }^{1, a}$

Sr. Editor. Vásquez Rubén D et al. publican el primer caso de probable transmisión vertical del virus de Influenza A $(\mathrm{H} 1 \mathrm{~N} 1)^{(1)}$. Aunque teóricamente es posible la transmisión del virus por esa ruta, haciendo un paralelo con lo documentado para influenza A H5N1, actualmente no hay evidencia científica de este contagio en la literatura mundial para H1N1 como bien señalan los autores.

Si bien es una gran limitante el no haber realizado los exámenes complementarios mencionados (aislamiento viral, los hallazgos histopatológicos en la placenta), hubiese sido de gran valor el aislamiento del virus en aspirado traqueo-bronquial, ya que este es más específico ${ }^{(2)}$. El hallazgo de un PCR positivo en un hisopado nasal dentro del contexto de una pandemia no necesariamente indica que esta sea causa de la infección de la vía aérea inferior.

Es de celebrar que tanto la madre como el niño salieron avante de esta comprometida situación, felicitamos a sus médicos por su compromiso con la ciencia y la atención clínica mostrada.

\section{Conflictos de Interés}

Los autores declaran no tener conflictos de interés.

\section{REFERENCIAS BIBLIOGRÁFICAS}

1. Vázquez RD, Chávez VM, Gamio IE, Muñoz RI, Polar MF, Montalvo R, Ticona E. Probable Transmisión Vertical del Virus de la Influenza A (H1N1): A Propósito de un Caso. Rev Peru Med Exp Salud Publica. 2010;27(3): 466-69.

2. Yuelong Shu, Hongjie Yu, Dexin Li. Lethal Avian Influenza A (H5N1) Infection in a Pregnant Woman in Anhui Province, China. N Engl J Med. 2006; 354 (913):1421-1422.

Correspondencia: José Luis Sandoval Gutiérrez. Dirección:Tlalpan 4502, Col. Sec XVI, Del.Tlalpan México D.F. México. CP 14080.

Teléfono: 548-71700; Ext. 5119.

Correo electrónico: sandovalgutierrez@gmail.com

\footnotetext{
1 Departamento de Medicina Crítica, Instituto Nacional de Enfermedades Respiratorias.

a Neumólogo Intensivista. Recibido: 03-01-11 Aprobado: 12-01-11
} 